\title{
EDITORIAL
}

\section{Por un lugar al sol}

\section{Dra. Susana Graciela Pérez Barrera ${ }^{1}$}

"Quien no sabe lo que busca no entiende lo que encuentra"

Claude Bernard (1813-1878)

La frase de Bernard es muy aplicable al tema que aborda esta edición de la Revista Sudamericana de Educación, Universidad y Sociedad.

Infelizmente, las personas con AH/SD continúan invisibles en los hogares, en las escuelas, en las empresas y en las políticas públicas de varios países de la región.

Cuando niños, siguen siendo expulsos de los centros educativos, incomprendidos, sufriendo bullying o diagnosticados equivocadamente y medicamentados. Cuando crecen, el desconocimiento o el conocimiento parcializado también los excluye y hasta los enferma por la omisión que los ha acompañado durante toda su vida.

Sus padres, que también sufren el desconocimiento y la falta de respuestas educativas, buscan desesperados un lugar donde puedan ser entendidos, apoyados y orientados.

Y la universidad, como órgano generador de preguntas, de conocimiento y de respuestas tiene papel fundamental en este panorama.

Por lo tanto, escribir este editorial es un enorme placer, porque estamos colaborando para esta transformación.

En primer lugar, porque es la primera revista completamente dedicada al tema de Altas Habilidades/Superdotación (AH/SD) en Uruguay, donde la producción científica en este campo es extremadamente pequeña y por eso ya es motivo de gran orgullo.

En segundo lugar, porque reúne artículos de algunas de las más destacadas autoridades en el tema en Sudamérica, encabezadas por una de las mayores referencias del mundo, el Profesor Dr. Joseph Renzulli.

En tercer lugar, porque viene como importante aporte científico para la inauguración del primer Curso de Especialización en Educación Inclusiva para Estudiantes con Altas Habilidades/Superdotación, que será ofrecido en el 2019 por la Facultad de Ciencias de la Educación de la Universidad de la Empresa, a cargo del Grupo de Investigación en Altas Habilidades/Superdotación (GIAHSD) y que ha sido seleccionado por la Agencia Nacional de Investigación e Innovación en la Convocatoria 2018 de Financiación para la visita de científicos y tecnólogos del exterior.

En este número que fue arbitrado por doctores y especialistas en el tema nacionales e internacionales en la modalidad de arbitraje doble ciego, varios expertos han cooperado con sus excelentes artículos.

A todo esto, la producción de alto nivel que aquí se presenta se suma a los insumos que han traído al GIAHSD las intensas actividades del 2018, como el Taller de Padres, la identificación de niños, adolescentes

1 Post-doctora en Educación (UFSM), doctora y magíster en Educación (PUCRS), Responsable por la Unidad de Investigación y Líder del Grupo de Investigación en Altas Habilidades/Superdotación de la Facultad de Ciencias de la Educación (UDE). Miembro del SNI. Investigadora becada Fulbright. sperezbarrera@ude.edu.uy 
y adultos con Altas Habilidades/Superdotación, el apoyo a docentes y centros educativos, la orientación técnica, el relevamiento de estudiantes de AH/SD en Argentina, Brasil y Uruguay que sigue en curso y la creación de su primer semillero que el año próximo comenzará a enamorar nuevos investigadores.

Por todo eso, nos congratulamos en presentar la sexta edición de la Revista Sudamericana de Educación, Universidad y Sociedad que también pretende inaugurar su nueva periodicidad semestral en el panorama académico y científico de nuestro país.

En este número, hemos contado con la colaboración de científicos emblemáticos del campo de Altas Habilidades/Superdotación que, desde Brasil, Estados Unidos, México y Uruguay nos han regalado sus contribuciones en diversas áreas de este tema.

El Profesor Dr. Joseph Renzulli y la Profesora Dra. Sally Reis, que no necesitan presentaciones, nos envían desde la NEAG School of Education de la Universidad de Connecticut (EUA) el artículo "The Three-Ring Conception of Giftedness: A Developmental Approach for Promoting Creative Productivity in Young People", que publicamos en su versión original y también traducido al español por la Mag. Karen Bendelman, a quien también agradecemos esta colaboración. Los autores describen primorosamente la ya famosa concepción sobre superdotación de los Tres Anillos y sus componentes, las características de quienes presentan ese comportamiento, la necesaria correlación entre la identificación y la atención educativa a estos estudiantes y el Modelo de Enriquecimiento para toda la escuela.

La Mag. Karen Bendelman, miembro del Board de California Association for the Gifted (EUA), conjuntamente con la Dra. (c) Natalia Colino de la Universidad de la República (Uruguay) y la Mag. Leticia Arbelo, por la Universidad Iberoamericana Internacional, México, nos escriben el artículo "Enriquecimiento tipo III: experiencias uruguayas en la atención de estudiantes con altas habilidades/superdotación". En él analizan cómo los docentes que participaron en un curso realizado en el Ministerio de Educación y Cultura por la Maestra Shirley Siri y la Mag. Bendelman, pusieron en práctica actividades de "Enriquecimiento Tipo III" (Renzulli \& Reis, 1997) y los cambios generados en la actitud de los estudiantes a partir de la incorporación de estas experiencias en el aula.

“Fatores que influenciam na dinâmica de famílias de superdotados" es el título del artículo escrito por la Dra. Jane Farias Chagas-Ferreira y la Mag. Sheila Perla Maria de Andrade de la Universidade de Brasília (Brasil), en el que presentan una revisión de literatura no sistemática que describe las influencias de los procesos de identificación, la precocidad, el asincronismo y las características individuales y socioemocionales de superdotados en la dinámica y relaciones familiares.

En el artículo titulado "Produção acadêmica de altas habilidades/superdotação: o que dizem os periódicos da educação física?", la Mag. Deizi Domíngues da Rocha, de la Universidade Comunitária de Chapecó (Brasil), y la Dra. Susana Graciela Pérez Barrera, de la Universidad de la Empresa (Uruguay) realizan un estudio bibliográfico de la producción académica relacionada a Altas Habilidades/Superdotación en los 21 periódicos científicos brasileños del área de Educación Física com mejor clasificación en el registro Qualis de CAPES publicados entre 2004 y 2015.

La Dra. Denise de Souza Fleith, de la Universidade de Brasília (Brasil), y la Mag. Marina Marques PortoRibeiro, de la Universidad Católica del Uruguay, nos brindan el artículo "Características desejáveis em professores de alunos superdotados", una revisión de literatura sobre las características deseables en docentes de estudiantes superdotados, en el que discuten la parcela de importancia que tienen los atributos cognitivos, la creatividad, los atributos personales y sociales y la formación profesional de los docentes encargados de educar estudiantes con AH/SD.

La Dra (c) Janete Tonete Suárez y la Dra. Solange Wechsler de la Pontifícia Universidade Católica de Campinas (Brasil) nos presentan el artículo que lleva como título "Mentoría de estudiantes talentosos", un estudio que analiza la percepción de 25 estudiantes de 8 y $9^{\circ}$ años de primaria identificados por sus docentes como personas con AH/SD sobre la importancia de un programa de mentoría para desarrollar sus talentos.

La Mag. Simone Miranda dos Santos Sviercovsky de la Universidad de la Empresa (Uruguay) nos ofrece el artículo “Inclusão Educacional: Alunos com Altas Habilidades/Superdotação na Educação Especial de Carambéi, Paraná, Brasil", resultado de un estudio de caso que tuvo como objetivo analizar la implementación de la inclusión escolar de estudiantes con AH/SD de $5^{\circ}$ y $9^{\circ}$ año de dos escuelas públicas de Carambeí. 
El artículo que lleva como título "O atendimento educacional especializado para os estudantes com altas habilidades/superdotação: reflexões sobre essa intervenção" de autoría de la Dra. Nara Joyce Wellausen Vieira, de la Universidade Federal de Santa Maria (Brasil), es producto de una investigación bibliográfica sobre la atención educativa especializada a estudiantes con AH/SD en aula o en la sala de recursos multifuncional, modalidad adoptada en el sistema educativo brasileño.

La Dra. Ângela Virgolim y el Lic. Thairone Emanuel Andriola Campos de la Universidade de Brasília (Brasil) son los autores del artículo titulado "inteligência e criatividade entre alunos bilíngues e monolíngues", en el que investigan la relación entre creatividad e inteligencia entre 24 alumnos adultos bilingües y monolingües de una institución pública de enseñanza superior que participan en un curso de lengua inglesa.

Finalmente, la Dra. María Alicia Zavala Berbena, Directora de investigación de la Universidad De La Salle Bajío (México), y Gabriela de la Torre García, directora del Programa Adopta un Talento (PAUTA), hospedado en el Instituto de Ciencias Nucleares de la Universidad Nacional Autónoma de México, nos ofrecen el artículo cuyo título es "Estrategias pedagógicas para la enseñanza de niños y jóvenes con altas capacidades intelectuales", que enfoca a la descripción de estrategias pedagógicas para dar atención educativa a niños y jóvenes con altas capacidades intelectuales en un contexto escolar, ya sea como parte de un programa de enriquecimiento de aula o en ambientes educativos agrupados y exclusivos para alumnos sobresalientes.

Nos enorgullece contar con la colaboración desinteresada de todos estos colegas y a ellos les agradecemos la posibilidad de brindarles a nuestros lectores nuevas miradas sobre un tema tan complejo y tan apasionante como este. 